Please do not remove this page

RMIT

UNIVERSITY

\title{
Re-imagining the role and function of higher education for alternative futures through embracing global knowledge futures
}

Gidley, Jennifer

https://researchrepository.rmit.edu.au/esploro/outputs/9921858379101341/filesAndLinks?institution=61RMIT_INST\&index=null

Gidley, J. (2012). Re-imagining the role and function of higher education for alternative futures through embracing global knowledge futures. In European Higher Education at the crossroads: Between the Bologna Process and National Reforms (pp. 1019-1037). Springer.

https://doi.org/10.1007/978-94-007-3937-6_51

Document Version: Accepted Manuscript

Published Version: https://doi.org/10.1007/978-94-007-3937-6_51 


\title{
Re-imagining The Role and Function of Higher Education for Alternative Futures through Embracing Global Knowledge Futures
}

Dr. Jennifer M. Gidley

Global Cities Research Institute

RMIT University, Melbourne

$\&$

President, World Futures Studies Federation

Email: jennifer@jennifergidley.com

\begin{abstract}
Weak signals from the early twentieth century indicate the emergence of new ways of thinking and knowledge patterns, which will be key drivers of change in the next 100 years. Significant developments can be mapped in most, if not all, of the major academic disciplines. In parallel, there is an emerging movement to integrate knowledge, to move beyond the fragmentation of knowledge associated with disciplinary specialisation via inter-, multi-, and trans-disciplinary approaches. In the current dominant model of higher education, disciplinary and ideological siloism thwart appropriate knowledge transfer - thus limiting the larger project of knowledge coherence so necessary if we are to cope with the complexity we must expect of the next 100 years. I propose that higher education can best be re-imagined through deeply embracing new ways of thinking and new knowledge patterns.
\end{abstract}

\section{Keywords}

Futures, Global, Integral, Knowledge, Planetary, Postformal, Transdisciplinary 


\section{Re-imagining The Role and Function of Higher Education for Alternative Futures through Embracing Global Knowledge Futures}

\section{Introduction}

Higher education as it currently operates in most of the world is more suited to the $19^{\text {th }}$ century industrial era than it is to the $21^{\text {st }}$ century. Yet so much has changed in the past 100 years, not just in terms of external developments, but also in terms of how we think and how we know. This paper identifies emergent signs of evolutionary change in human thinking that run parallel with many of the exponential changes manifesting in the external world. Futures studies provide a macro-temporal framing for these changes by exploring the last 100 years in order to prepare for the next hundred years. Weak signals from the early twentieth century indicate the emergence of new ways of thinking and knowledge patterns, which will be key drivers of change in the next 100 years. The new ways of knowing are referred to in the psychological literature as postformal reasoning, include creativity, imagination, dialogue and the ability to handle paradox.

Throughout the $20^{\text {th }}$ century, and increasingly in the last forty years, significant developments can be mapped in most, if not all, of the major academic disciplines. New ways of thinking within the disciplines of science, philosophy, psychology and education will be discussed. In parallel, there is an emerging movement to integrate knowledge, to move beyond the fragmentation of knowledge associated with disciplinary specialisation via inter-, multi-, and trans-disciplinary approaches. Transdisciplinary approaches such as futures studies and planetary/global studies will be discussed. In spite of these strengthening developments within and across many disciplines and knowledge fields, the institution of mass education, designed for the industrial era, has been pretty static since the onset of the industrial revolution.

In the current dominant model of higher education, disciplinary and ideological siloism thwart appropriate knowledge transfer - thus limiting the larger project of knowledge coherence so necessary if we are to cope with the complexity we must expect of the next 100 years. I propose that higher education can best be re-imagined through deeply embracing new ways of thinking and new knowledge patterns.

While the remnants of neoliberal capitalism argue for the new "knowledge economy" this economics-dominated thinking perpetuates fragmentation, commodification and instrumentalism. By contrast the new ways of knowing proposed here are grounded in human creativity, innovation and relationship, less dependent on economic and material resources and thus intrinsically more sustainable for a fragile planet.

\section{Drivers of Change for Higher Education Futures}

Over a decade ago, educational researchers with an eye to the future identified several key drivers of change as being key shapers of university transformation: globalism, multiculturalism, virtualization and politicization (Inayatullah \& Gidley, 2000).

- Globalism - the freeing of capital and the taming of labor and nation-states, particularly those in the South; 
- Multiculturalism - an understanding that while reality is socially constructed and we create gender and culture through practice; cultures, civilizations, and women and men know the world differently, and that a good society must authentically reflect this diversity;

- The internet - in all its meanings from the site, the form, the delivery system to the content of the new universities, particularly in the possibility of the creation of the virtual university and decentralized publishing; and

- Politicization - in the South this refers to increasing attempts to use the university for repressive measures as well as the university as a site of dissent, and in the North it relates to the university being part of the economic rationalization of society, of the post-industrial problematique.

At the time, globalism and politicization were viewed as fully developed, longterm historical trends, while multiculturalism and the Internet were viewed as more emergent. From another standpoint, the International Commission on Education for the $21^{\text {st }}$ Century developed four pillars of education-learning to be, learning to know, learning to do and learning to live together. These were aimed at shifting the educational focus from "the local community to a world society", from "social cohesion to democratic participation" and from "economic growth to human development" (Delors, 1996).

Just 10-15 years later, some of these drivers have morphed into other forms and some new drivers of change have emerged. While accepting the ubiquity of the above four drivers, this paper expands on some of the more extended impacts of globalism through the globalization of higher education. It also points to the need for higher education to embrace the new ways of thinking and new knowledge patterns and to shift emphasis from the metaphor of the global knowledge economy to a metaphor of global knowledge futures where higher education re-values the importance of imagination, creativity and innovation as ways of knowing suited to the complexity of the $21^{\text {st }}$ century. The new drivers of change identified in this paper include:

- Globalization of higher education

- The tension between elite institutions and mass higher education

- Changing views of quality in higher education and social inclusion

- New ways of thinking and systems of knowledge

- The shift from the global knowledge economy to global knowledge futures

\subsection{Globalisation of Higher Education}

As the politico-economic processes of globalisation increasingly impact on sociocultural spheres, the higher education sector in the $21^{\text {st }}$ century is faced with new and more complex challenges across the globe. The tensions between global, national and regional/local interests found in other discourses are spilling over into the higher education literature.

By the 1990s a subtle shift had taken place in Europe by which the previous "national and cultural role" of higher education was being eclipsed by "the economic rationale" (Huisman \& Van der Wende, 2004). Jeroen Huisman notes that in spite of initial resistance and critique from the higher education sector, the economic rationale was intensified by both globalisation and the rise of information and communication technologies. He argued that "this trend spurred international competition" within higher education (Huisman \& Van der Wende, 2004, p. 350). This issue of global 
competitiveness - so central to the functioning of neoliberal economic markets - has penetrated the higher education sector. Indeed,

This international competitive stance not only relates to the export of higher education, but also to issues of quality. For instance, the Austrian government has established an accreditation mechanism that may be interpreted as a shift towards international competition (instead of cooperation). (Huisman \& Van der Wende, 2004, p. 354)

Yet the complexity of our times allows new scope for "cross-border initiative and invention in both knowledge and university strategy" (Marginson, 2007). Such transversing of borders is exemplified by The European Commission Bologna Process, ${ }^{1}$ part of the "European agenda towards converging systems of higher education." In this regard Huisman claims that, "in less than 10 years, harmonisation (although preferably called 'convergence') of higher education structures changed from an undesirable objective to a highly advisable aim." (Huisman \& Van der Wende, 2004, pp. 349-350)

Globalisation has also stimulated mobility (of students, academics and ideas) with the unexpected effect of enabling new insights into the diversity of higher education systems (Lunt, 2008). Both established and newer higher education institutions in the North and the South compete for market share in the knowledge economy to prevent "brain drain" (Huisman \& Van der Wende, 2004), to foster "brain gain", "brain circulation" and global talent flows (Welch \& Zhen, 2008). Marginson notes that student mobililty is asymmetrical whereby "some nations are primarily exporters, others are primarily importers" (Marginson, 2004, p. 202). New discourses have emerged on international education, comparative education and global education. The rise of international, transnational and supranational organisations has furthered the drive to restructure.

The rise of the global south in terms of higher education provision is another significant outcome of this process, with China, India, Malaysia, and Saudi Arabia being new key players in the global higher education sector. The UNESCO-funded International Association of Universities is a leader in this area, with the biennial Global Higher Education Forum (GHEF) in Malaysia being an emerging worldleading event. Notably, GHEF is collaborating with the World Futures Studies Federation $^{2}$ for a Conference in Penang, December 2011 on "Global Higher Education: Reflecting on the Past, Designing Sustainable Futures."

\subsection{The Tension between Elite Institutions and Mass Higher Education}

There is little contention that in the last few decades we have witnessed a shift in higher education policy, at least in the Anglo-European context, from universities as elite institutions for the few to higher education as a birthright of the many. This shift is well exemplified in the UK higher education policies of the 1990s. Ingrid Lunt summarised the challenges that the UK higher education system faced at the beginning of the Blair government, noting that similar challenges were arising at the

\footnotetext{
1 "The Bologna Process aims to create a European Higher Education Area in which students can choose from a wide and transparent range of high quality courses and benefit from smooth recognition procedures." http://ec.europa.eu/education/policies/educ/bologna/bologna en.html

${ }^{2}$ This event is a collaborative venture with the $21^{\text {st }}$ World Conference of the World Futures Studies Federation, founded in Paris in 1973. http://www.wfsf.org/
} 
time in the HE systems of all developed countries. Lunt claimed that "the shift from an elite to a mass HE system" led to decreases in public funding to universities creating increased financial challenges. She also argued that the higher education sector felt a need to respond competitively because of beliefs in "the link between the economy and the knowledge and skills of the labour force." The result, she claimed was the so-called "high skills economy" and the "commodification of knowledge" (Lunt, 2008, p. 742).

As a counter trend there is evidence in the last few years to suggest the pendulum may be swinging back. While some researchers applaud the concept of the Emerging Global Model (EGM) of the elite 21st century research university, claiming that such "top stratum of research universities worldwide" are key to "economic and social development" (Mohrman, Ma, \& Baker, 2008), this is not the whole picture. Mohrman et al. identify eight characteristics of the EGM: global mission, research intensity, new roles for professors, diversified funding, worldwide recruitment, increasing complexity, new relationships with government and industry, and global collaboration with similar institutions (Mohrman et al., 2008). However, other researchers raise new questions about the impact of such a concentration of resources on higher education more broadly in Europe and Asia (Deem, Mok, \& Lucas, 2008). OECD Analyst Jaana Puuka reminds us that the "new wider mission of higher education institutions, often characterized as a 'third task' or social obligation, can be best mobilized in the context of regions" (Puuka \& Marmelojo, 2008). This third task is aligned to Boyer's scholarship of application (Boyer, 1990).

Marginson claims that the current "transnational markets in higher education are structured as a segmented hierarchy" reflecting dominance/subordination in three aspects: between "developed" and "developing nations"; between English and nonEnglish language universities; and between "the hegemonic power of the United States in world higher education" and higher education in the rest of the world (Marginson, 2004, p. 218). He goes as far as to claim that "the old equality of opportunity project is now in terminal crisis, and will continue to be undermined by heightened status competition, markets, cross-border leakages of people and resources, and global commercialisation" (Marginson, 2004, p. 234).

In the light of these developments must we conclude that the notion of quality in higher education has again been hijacked by elite institutions at the expense of mass education? Or is there a way that quality in higher education may be viewed more systemically, more integrally?

\subsection{Changing Views of Quality in Higher Education and Social Inclusion}

This next section explores what is meant by quality in higher education. While the emerging discourse on EGMs suggests that quality in higher education is dependent on research and funding concentration and can be measured by league tables and other performance indicators, it needs to be recognised that this view is underpinned by a particular ideology. The idea of EGMs has emerged from a global knowledge economy based on the freemarket neoliberal ideology where individual institutions compete with each other. That this ideology, neoliberalism, is the dominant one-and thus invisible in much of the discoursedetail elsewhere (Gidley, 2010b).

The UK provides a good case study of the tension between the elite notion of quality in higher education and the social justice ethic towards greater access to higher education. Lunt refers to this as "the trade-off between excellence and equity" 
(Lunt, 2008). She notes "the total increase in participation rates masks a considerable variation by social class" (Lunt, 2008) reflecting the paradoxes and tensions even when a government such as that of New Labour attempts to balance the global competitiveness with social inclusiveness and equity. Although Blair's policy rhetoric gave equal weighting to an espoused commitment to "social inclusion and equity", this did not have the significant impact on universities effected by his "enhanced global competitiveness" policy (Lunt, 2008). While the prior conservative agenda led to dramatic increases in access to higher education - an increase of one-third in overall student numbers - by 1997, "this expansion had not succeeded in reducing class inequalities" (Lunt, 2008, p. 742).

Similar observations have been made in Australia: "the effect of interventions based on this liberal position has been to maintain the status quo of power and privilege with exception proving the rule" (Nunan, George, \& McCausland, 2005, p. 252). Marginson claims:

Neo-liberal marketisation raises sharper questions about social inequality in higher education, in two dimensions: equality/inequality of access to opportunity, and equality/inequality of the opportunities themselves. All else being equal, economic markets are associated with greater social inequalities of access in systems mediated by the private capacity to pay, so that access is more steeply stratified on social lines; and with a steeper hierarchy of institutions, so that what is accessed is also increasingly stratified. (Marginson, 2004, p. 234)

The default neoliberal idea of quality as a measure of a particular university or a particular nation's competitive edge is not the only measure of quality. Two broader notions of quality in higher education need to be systemically strengthened in the whole domain of higher education globally. From the ideology of justice globalism, global networks of higher education institutions would collaborate rather than compete with each other. ${ }^{3}$ And from the perspective of human potential ideologies, quality in higher education would mean more than global competitiveness or higher levels of access, but would be related to human potential and transformation. These expanded notions of quality have been discussed in more detail elsewhere (Gidley, 2010b).

\section{New Ways of Thinking and Systems of Knowledge}

Imagination is more important than knowledge. For while knowledge defines all we currently know and understand, imagination points to all we might yet discover and create. Albert Einstein

It is not enough for higher education futures to be primarily focused on external "trends" such as globalisation, thus overlooking the major paradigm shifts rocking the foundations of knowledge for the last half-century. This paper argues that the "megatrends of the mind" are as important for higher education futures as the megatrends in the external world (Gidley, 2010c). A broad-based global scan of the epistemological developments both within and across disciplines provides

\footnotetext{
${ }^{3}$ The latter ideology is reflected in the title of the recent IAU conference: "Associations, Networks, Alliances etc.: Making Sense of the Emerging Global Higher Education Landscape" 2009 Conference of the International Association of Universities, IAU: For A Worldwide Higher Education Community, Mexico.
} 
considerable evidence that leading thinkers have begun to enact new ways of thinking to such a degree that most academic disciplines have undergone a major paradigm shift throughout the $20^{\text {th }}$ century.

\subsection{Disciplinary Shifts reveal New Ways of Thinking}

Major shifts have occurred within scientific, philosophical and other disciplines since the beginning of the $20^{\text {th }}$ century.

\subsubsection{Scientific shifts}

The modernist, formal, scientific worldview, based on Cartesian dualism and classical physics - with its static notions of a mechanical, "building block" universe of atoms - is gradually being replaced by postmodern, postformal worldviews. This paradigmatic shift has arisen from developments in general systems theory, chaos theory and complexity sciences. Within science itself classical physics based on Newtonian mechanics has given way to new physics theories arising from Einstein's theory of relativity and the discoveries of quantum physics (Einstein, 1920/2000; Zajonc, 2004). In parallel there has been a shift in scientific fundamentals from a dominant emphasis on physics to new biological discourses. The epistemological shift from physics to biology mirrors the difference between the objects of study - the domain of the physical to the domain of life (Bertalanffy, 1969/1976). Following the shift from classical to quantum physics there has been a transition from classical biology, including Darwin's theories of evolution to the new biology-based theories of self-organisation and emergence (Deacon, 2003; Goodenough \& Deacon, 2006; László, 2007; Russell, 2000). The more fluid, life-oriented worldviews arising from this biological turn emphasise life as being "a complex adaptive system" (Swimme \& Tucker, 2006), "self-organising" (Jantsch, 1980; Varela, Thompson, \& Rosch, 1993), and "emergent" (Goodenough \& Deacon, 2006).

\subsubsection{Philosophical shifts}

A similar transition can also be observed in Western philosophical thought throughout the $20^{\text {th }}$ century from modernism to postmodernism and poststructuralism. The singular notion of "philosophy"-implying British analytic philosophy, linked to logical positivism - has been increasingly accompanied by a greater "philosophical pluralism"(Mandt, 1986). Though more marginalised than the shifts from classical physics and biology to the new sciences, a philosophical turn from static mechanistic metaphors to organic, living, process metaphors of thinking was also emerging in philosophical thought in Einstein's time (Bergson, 1911/1944; Steiner, 1894/1964; Whitehead, 1929/1985). Henri Bergson's élan vital, Alfred North Whitehead's process philosophy and Husserl's lifeworld were all inspired by these shifts. Early $20^{\text {th }}$ century philosophers, such as Rudolf Steiner, William James and John Dewey, attempted to integrate these emerging organic, natural, biological understandings with the scientific discourses of their day. Interestingly, such ideas were already appearing a century prior, in the leading edge thinking of Goethe's "delicate empiricism" and Schelling's "nature philosophy." Philosophical approaches that point to constructive or reconstructive postmodernisms tend to draw on the organic, process philosophies of Bergson and Whitehead (Griffin, 2002). 
More recent philosophical developments include: comparative philosophy, critical social theory, eco-philosophy, hermeneutics, integral theory, postmodernism and poststructuralism.

\subsubsection{Educational Shifts}

The last few decades have also born witness to the beginnings of a transition from formal, factory-model school and university education to a plurality of postformal pedagogies. We are experiencing what I call a third wave of impulses to evolve education since the beginning of the 20th century. The first and second waves have been discussed elsewhere (Molz \& Gidley, 2008). I refer broadly to these third wave approaches to evolving education as "postformal pedagogies." Most have emerged over the last decade. I have identified over a dozen emerging pedagogical approaches that reflect new ways of thinking, which facilitate the evolution of consciousness (For references to the literature in relation to these approaches see (Gidley, 2009). These include:

- Aesthetic and artistic education;

- Complexity in education;

- Critical and postcolonial pedagogies;

- Environmental/ecological education;

- Futures education;

- Holistic education;

- Imagination and creativity in education;

- Integral education;

- Planetary/global education;

- Postformality in education;

- Postmodern and poststructuralist pedagogies;

- Transformative, spiritual and contemplative education;

- Wisdom in education.

Lest this list give the appearance that education globally in the $21^{\text {st }}$ century is alive and well, creative and innovative, it is worth noting that all of these are relatively small counter-streams to the dominant hegemonic factory model of education. Further there is a neo-conservative backlash within the field of education that seeks to control curricula through the "audit culture" (MacLure, 2006). One of my interests is to foster dialogue between these postformal pedagogies to strengthen their awareness of each other and to increase knowledge transfer among them.

\subsection{Beyond Disciplinary Boundaries to New Systems of Knowledge}

In parallel with these disciplinary developments, disciplinary specialisation itself is being transcended. Several epistemological approaches have emerged in the second half of the $20^{\text {th }}$ century that seek to counterbalance the excesses of fragmentation, specialisation and reductionism in the dominant worldview. These include transdisciplinarity, systems theory, integral studies and others. As knowledge breaks the disciplinary boundaries it also moves beyond old conceptions of time and space. 


\subsubsection{Post-disciplinarity as a Knowledge Bridge}

New attempts are being made to create knowledge-bridges among disciplines. There has been a developing transition from disciplinary specialisation to multi-, inter-, transdisciplinary knowledge creation (Klein, 2004; Morin, 2001; Nicolescu, 2002). The coining of the term transdisciplinarity in the late 1960s has been attributed to Jean Piaget, though others such as Edgar Morin and Erich Jantsch used it around the same time (Nicolescu, 2003). Several other developments can be noted in the way that knowledge is constructed in order to be studied. For example, there has been a flourishing of post-disciplinary studies grounded in notions of social justice (such as cultural studies, indigenous studies, queer studies, women's studies/feminism); and other issues of critical importance (such as environmental studies, justice globalism, peace studies, media studies). In relation to the latter the implications of the information age, particularly the world wide web need to be particularly noted for their ubiquitous and controversial effects on other areas of knowledge creation (Gidley, 2004; Healy, 1998; Steinberg \& Kincheloe, 2004).

\subsubsection{Integration of Knowledge}

Higher education theorists and practitioners need to seriously consider the emergence of systemic, holistic and integral thinking in various fields of knowledge. At around the same time that transdiscipinarity was first being discussed in France, theoretical biologist Ludvig von Bertalanffy initiated important developments in establishing a theoretical case that the methods of classical physics were not appropriate for studying biological life (Bertalanffy, 1969/1976). He developed the theory of open systems, claiming that traditional closed system models based on classical science were "in principle, inapplicable to the living organism... [and] that many characteristics of living systems which are paradoxical in view of the laws of physics are a consequence of this fact" (p. 39-40). Systems science is a significant theoretical basis of László's integral theory (László, 2007) and Hans Georg Graf's global futures approach (Graf, 2002). The importance of knowledge integration was highlighted over twenty years ago by Ernst Boyer (Boyer, 1990).

\subsubsection{Expanding Space through Global/planetary Perspectives}

Recent decades have witnessed a political movement from the centrality of nationstates to more global and planetary perspectives, and hybrid concepts of global/local, glocal and even glonacal. The modernist worldview is closely linked with the geopolitical unit of the nation-state. Yet there is a growing complexity and urgency of planetary issues from socio-cultural, politico-economic and environmental perspectives - such as increasingly inequitable wealth distribution, climate change, mass extinction of species and water shortages. These require more than piece-meal, fragmented responses and demand a planetary reframing of human relationships with nature and the cosmos. This is also reflected in the relatively recent eclipsing of fields such as international studies (grounded in the concept of the nation-state) by the more comprehensive, inclusive and multi-polar field of global studies (Sassen, 2007). It is also reflected in the increasing reference to global and planetary in relation to consciousness, culture and civilisation (Elgin, 1997; Montuori, 1999; Swimme \& Tucker, 2006). This shift is reflected in futures research as an emphasis on planetary, world or global futures. 


\subsubsection{Expanding Time: The Emergence of Futures Studies}

Another 1960s development was the gradual transition from emphasis on the past to awareness of the value of foresight/futures thinking in many discourses. This provided a positive scientific and academic context for futures studies to expand its scope. By futures studies I refer to the transdisciplinary, transnational and multisectorial field, which includes thousands of academics and practitioners, many of whom operate globally. I take a pluralistic approach to the field, which is detailed elsewhere (Gidley, 2010d).

In addition there has been a stretching of time periods that can be "legitimately" studied, e.g. macrohistory (Galtung \& Inayatullah, 1998) and big history. The concept of linear time itself has undergone significant change since its tripartition into past, present and future by Parmenides (b. 540 BCE) (Gebser, 1949/1985). Over the last two millennia the linear conception of time - which began as the more formal measurement of already-recognized cosmic and natural temporal cycles-became rationally conceptualized as the chronological measurement of change. Since the Industrial Revolution linear, chronological time has further contracted by association with mechanical time and factory time.

However, the changes to the concepts of time have been even more dramatic in the last century since Einstein. In the early 20th century significant theoretical developments concerning the notion of time occurred in both the natural sciences and the social sciences. In physics, Einstein's theory of relativity displaced the Newtonian conception of objective time as an unchangeable, permanent 'place' upon which the movement or change of things can be measured in discrete, identical fragments (Einstein, 1920/2000; Weik, 2004). Theoretical attempts have been made to come to terms with these new perspectives on time (Adam, 2004; Gidley, 2007).

Scientific and technological developments in the last century have seen temporal partitioning become exaggerated by increasingly sophisticated scientific and digital means, from one extreme in radioactive half-life, to the other extreme in nanoseconds. Linear time has also become dominated by politico-economic metaphors, exemplified by such phrases as "time is money," "buying time." This mechanistic and economic colonization of time has increased exponentially in recent decades, contributing to the speed addiction of our present age-demonstrated in fast foods, internet, instant global text messaging, accelerated learning, and the three-quick-steps-to-spiritualenlightenment culture. Just to cope there are drugs to keep up, such as speed and cocaine; and drugs to slow down, such as alcohol and tranquillizers.

\subsection{The Frontiers of Global Knowledge Futures}

Arising from my evolution of consciousness research I became aware of the significance of several discourses that either identify and/or enact new paradigm thinking, including postformal studies, integral studies and global/planetary studies (Gidley, 2007, 2010d).

Postformal is the most widely used psychological term to denote higher developmental stages beyond Piaget's formal operations. Adult developmental psychologists have been undertaking research into postformal thinking for several decades particularly in the USA. They identify numerous features of postformal reasoning - including complexity, contextualisation, creativity, dialectics, dialogue, holism, imagination, paradox, pluralism, reflexivity, spirituality, values and wisdom 
(Cook-Greuter, 2000; Kegan, 1994; Kohlberg, 1990; Sinnott, 1998). Michael Commons et al. have identified up to four postformal stages of psychological development: systemic, meta-systemic, paradigmatic and cross-paradigmatic (Commons \& Richards, 2002). Postformal studies also includes the work of educational researchers who use the hyphenated form of post-formal in relation to critical and postmodern approaches to education (Kincheloe, Steinberg, \& Hinchey, 1999). Educational researcher Joe Kincheloe referred to post-formality as "the sociocognitive expression of postmodernism” (Kincheloe \& Steinberg, 1993, p. 309).

Integral is a widely used term by several different schools of thought. The use of the term 'integral' or 'integrative' has become increasingly common in leading edge approaches to many disciplines. Some significant $20^{\text {th }}$ century and contemporary writers working from a substantially integral perspective include, Rudolf Steiner, Michael Polanyi, Jean Gebser, Sri Aurobindo Ghose, Ervin László, Ashok Gangadean, William Irwin Thompson and Ken Wilber. An important basis of the idea in its varied forms is that the complexity of the present times requires higher-order forms of thinking that go beyond the narrow specialisations of instrumental rationality. Integral approaches include multiples ways of knowing, being and acting in the world. By integral studies I include the various discourses that explicitly refer to their theoretical approaches as integral (such as Gebser, László, Sri Aurobindo and Wilber) and also those that can be regarded as integral according to the integrality of their approaches (such as Morin, Nicolescu and Steiner). The first group explicitly identifies integrality and to greater and lesser degrees also enacts it. The second group - while not so explicit about the term - comes close to enacting integrality.

The term planetary has been increasing in usage within the evolution of consciousness and futures discourses. The pluralism of its contemporary usage provides a counterbalance to the term, globalisation - which has often been limited to politico-economic discourse and processes. Many researchers who use planetary have been inspired by Teilhard de Chardin's notion of the planetization of mankind (Teilhard de Chardin, 1959/2004). The term, planetary — which primarily denotes an anthropo-socio-cultural and ecological framing - is gaining increasing currency as a term to characterize important features of the new consciousness, particularly for those theorists who have a critical sensibility in the light of our complex current planetary situation. In addition to its popular use by environmental activists it is used in academic contexts by a range of philosophers, scientists, educators and sociologists. This critical use of planetary has been emphasised in the writings of French philosopher, Edgar Morin who refers to the present times as the Planetary Era, which he claims began around five hundred years ago (Morin, 2001; Morin \& Kern, 1999). By global/planetary studies I refer to the emerging discourses that use the term planetary in the following contexts: critical environmental (biosphere), transcultural (anthropo-socio-sphere), philosophical (noosphere) and spiritual interests (pneumatosphere). I also include the political science and international relations literature that points to the shift from nationalistic to transnational and planetary/global worldviews.

\section{From Global Knowledge Economy to Global Knowledge Futures}

\subsection{The Global Knowledge Economy}

"Where is the wisdom we have lost in knowledge? Where is the knowledge we have lost in information?" 
We hear a lot today about the 'knowledge economy' yet this economistic framing fails to attend to the richness and diversity of knowledge creation that is being enacted on a planetary scale. We also hear the term 'information era' as if it were a complete encapsulation of the present phase of cultural evolution. The proponents of the 'information era' generally fail to attend to the evolutionary move beyond mere 'information' to new ways of knowing, new knowledge patterns and the emergence of knowledge integration.

At the close of the first decade of the $21^{\text {st }}$ century, some of the most creative, innovative, and dynamic knowledge around the globe is being produced and disseminated outside mainstream universities. Academic researchers and research council bureaucrats need to take heed. Now that "knowledge production", "knowledge transfer", and "knowledge dissemination" have become core commodities of the increasingly competitive global knowledge market economy, how will universities and their research centres keep up?

While the juggernaut of old-paradigm thinking keep its hold on educational institutions the burgeoning of new knowledge "paradigms" is breaking through from the periphery. A plethora of private providers, social movements, niche research institutes, open source resources, edutainment and, of course, the ubiquitous information kaleidoscope of the world wide web, make it increasingly difficult for the former bastions of knowledge production and dissemination - formal educational institutions to compete for "market-share." But is competition the best way forward? Could it be that the leadership of universities and research councils need to listen more deeply to the periphery - to the new, unorthodox developments in the creation and dissemination of knowledge?

\subsection{Towards Global Knowledge Futures}

"One of the greatest problems we face today is how to adjust our way of thinking to meet the challenge of an increasingly complex, rapidly changing, unpredictable world. We must rethink our way of organising knowledge." (Morin, 2001, p. 5)

The two quotes opening this and the previous section speak of knowledge. The first is from American-British poet, T. S. Eliot, and the second is from French philosopher, Edgar Morin. Eliot bemoans the loss of wisdom while Morin hints at its re-awakening. Perhaps it takes the eye of an artist, a poet, to perceive the loss of wisdom in the stripped-down, prosaic pragmatism of the Information Era. Yet it is a philosopher - a lover of wisdom — who actively thinks towards more complex ways of organizing knowledge in the Planetary Era.

In my reading of Morin's work it becomes immediately evident through the philosophical and poetic richness of his language and concepts that his notion of knowledge is already filled with the type of postformal, integral, planetary wisdom and foresight that is being gradually articulated in the frontier discourses discussed above. As Eliot indicates, the modern era of hyper-rationality and hyperspecialization has been a reductive process in which the pre-modern unitive worldview of inherited, or revealed, "wisdom" has been superseded by bits - and, more recently, bytes - of information. In this context, the term "new knowledge" is often used to mean new technologies. 
In addition to this fragmentation, commodification of knowledge abounds as a socio-cultural by-product of globalization. Borrowing heavily from industrial era metaphors, education is now marketed as the "product" in a globally competitive "knowledge industry."

The insinuation of neoliberal economic theory into all walks of life-including education - has led to the reframing of education as a subset of the new "knowledge economy." In this new knowledge economy we can witness nations and regions scrambling to grab market-share through creating "science parks", "education cities" and "knowledge hubs." The most disturbing aspect of this "globalization of knowledge" is that it frequently reflects homogenization. This McDonaldization of education transplants outmoded models and approaches as if they were fast-food franchises with little regard to the quality of the learning experience for students or the cultural context in which the model is implanted. In the rush to the top of the globally competitive league tables there appears to be a blind disregard for epistemological and cultural diversity, through alternative ways of knowing. With their embeddedness in the global economy such approaches to global knowledge are also locked into short-termism, stasis and homogenization. See Figure 1.

Figure 1: Global Knowledge Economy - Ideological Stasis and Homogenisation

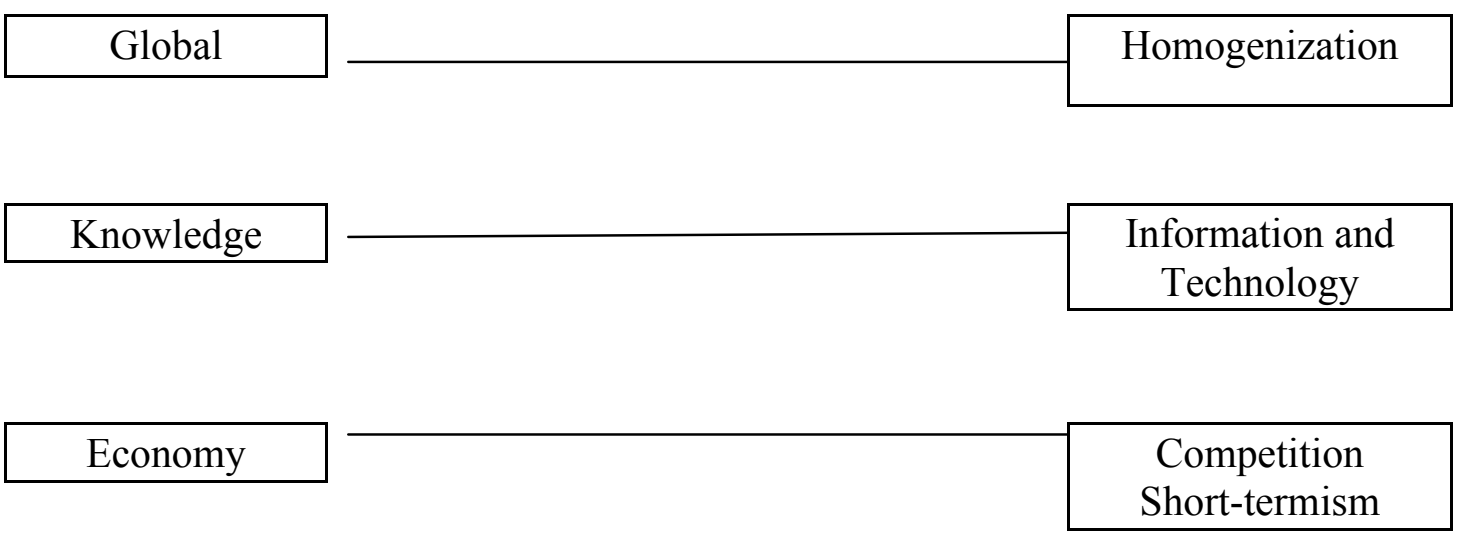

In contrast to the reductive and economistic ideologies underlying the notion of the "global knowledge economy" my term "global knowledge futures" is intended to unsettle those who use the term knowledge reductively and/or prescriptively. "Global knowledge futures" includes research that eschews the mechanistic, instrumental, reduced versions of knowledge. It seeks to go beyond, to go deeper, to imagine longer time-scales and planetary spaces, to develop and enact more coherent futures of knowledge integration.

My notion of global knowledge futures is framed within the understanding that human consciousness is evolving and for the first time in history we can consciously participate in co-creating our futures through conscious evolution. Although the notion of evolution is frequently attributed to Charles Darwin, the concept was originally seeded by several integrally-oriented German Idealists and Romantics, towards the end of the $18^{\text {th }}$ century (Gidley, 2010a).

In parallel with the dawning of integral evolutionary thinking in the German states, the Industrial Revolution - a key marker of modernity — was brewing in Britain, with both progressive and disruptive socio-cultural impact. Grounded in the paradigm of 
logical positivism, which spawned scientific materialism and analytic philosophy, mechanistic notions of human nature cast a shadow on idealist and spiritual notions of human being and consciousness. Since Darwin - and in spite of his under-appreciated writings on love and moral evolution (Loye, 1998, 2004) - the dominant evolution discourse has privileged materialistic bio-mechanical worldviews. More philosophical and spiritual worldviews, e.g. those of the German idealists and romantics, were pushed to the margins being regarded as unscientific. However, several leading thinkers in the early to mid $20^{\text {th }}$ century carried forward the philosophical and spiritual evolutionary ideas of the idealists and romantics (Aurobindo, 1914/2000; Gebser, 1949/1985; Steiner, 1904/1993, 1926/1966; Teilhard de Chardin, 1959/2004). They kept alive the notion that human consciousness is evolving beyond materialistic, instrumental rationality to embrace more complex, creative, integral, spiritual ways of thinking and knowing. Yet overall their work has been largely academically ignored. More recently, evolution of consciousness theories have been picked up and further developed-being ripe for more comprehensive and collaborative articulation through the $21^{\text {st }}$ century. Numerous contemporary theorists from a variety of disciplines have begun to research the evolution of consciousness from a more integral perspective (Gangadean, 2006; Gidley, 2007; Hart, 2001; Montuori, 1999; Morin \& Kern, 1999; Swimme, 1992; Thompson, 1998; Wilber, 1980/1996, 1981/1996).

The philosophical and theoretical writings that discuss the emergence of a new movement/stage/structure of consciousness are also supported by some longitudinal research. An emerging change in consciousness was proposed in a study undertaken in the USA over ten years, reporting on the rise of "integral culture", and identifying almost a quarter of Americans as "cultural creatives" (Ray, 1996). In addition, a 43nation World Values Survey, including Scandinavia, Switzerland, Britain, Canada and the United States concluded that: "a new global culture and consciousness have taken root and are beginning to grow in the world"- the postmodern shift (Elgin, 1997).

Building on the evolution of consciousness literature my phrase global knowledge futures can be teased out semiotically to clearly distinguish it from the hyper modernist global knowledge economy. The cultural pluralism implied in my notion of global, and the ideological diversity in my notion of futures, fold back into the term knowledge, enriching it and opening it up to insights from the frontier discourses discussed above that are central to global knowledge futures. See Figure 2. 
Figure 2: Global Knowledge Futures - Dynamic Unity in Dialogue with Diversity

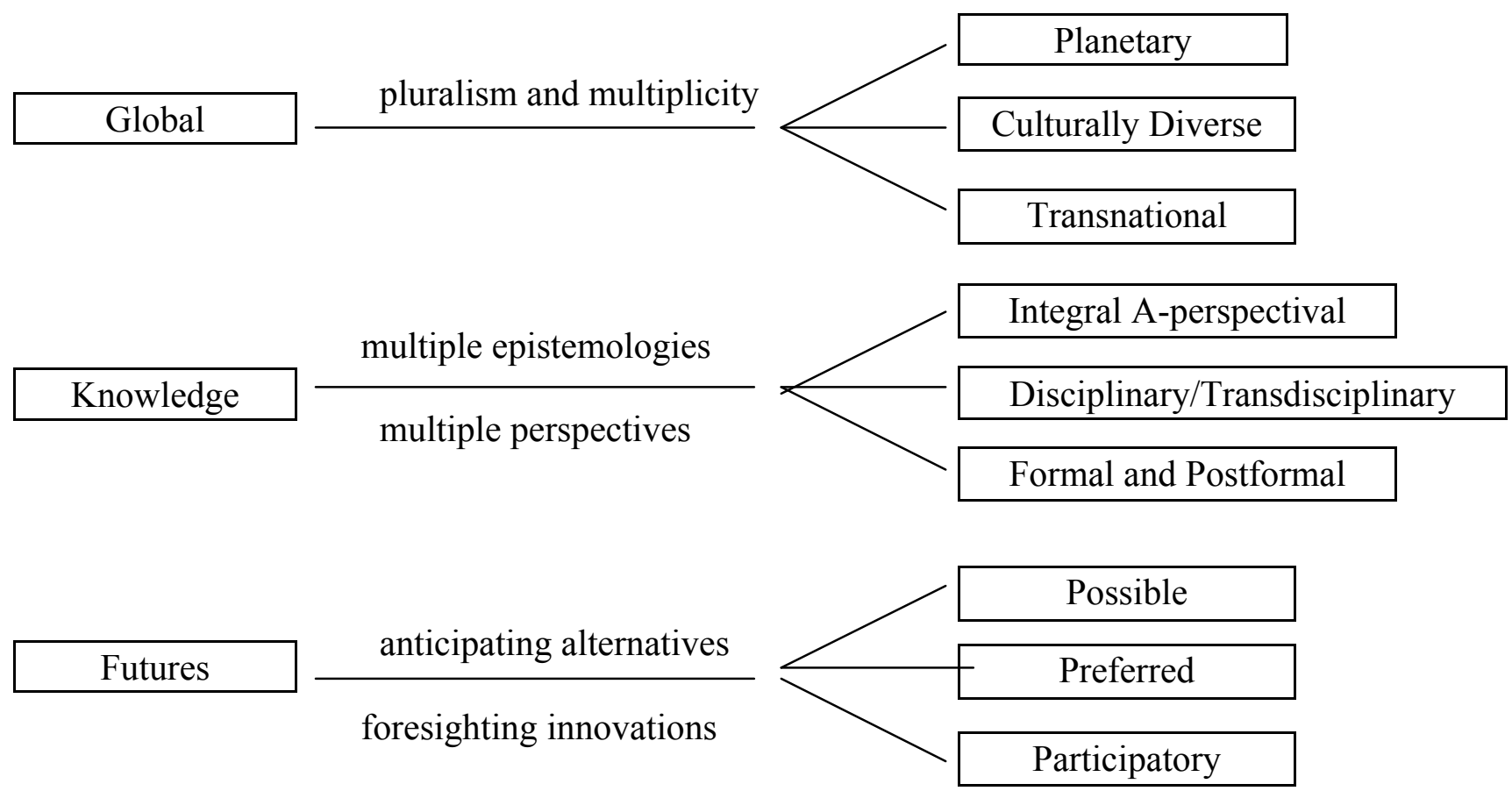

\section{Anticipating Visionary Futures of Global Higher Education}

Higher education researchers and practitioners who move beyond a business-asusual stance, to embrace new ways of thinking and patterns of knowledge, would benefit from integrating the following $20^{\text {th }}$ developments in thinking.

- post-classical sciences including quantum physics, chaos and complexity, emergentism, open systems;

- postmodern, poststructuralist and comparative philosophies;

- critical, interpretive and contextual theories;

- postformal reasoning, including complexity, creativity, paradox, reflexivity;

- postformal pedagogies;

- foresight and long-term futures thinking;

- global and planetary perspectives;

- systemic, holistic and integral theories;

- inter- and transdisciplinarity.

The following issues also need serious futures thinking and attention from higher education experts:

- Environmental degradation now includes more dramatic climate conditions;

- After the "GFC" the limits to growth discourse is even more pertinent;

- Social and global justice are far from commonplace;

- Cultural pluralism and the needs of the global south require sustained focus;

- The factory model of formal education needs to be "postformalised." 


\section{Reflections}

The systemic knowledge shifts of the last century are facets of complex processes that are as yet little understood in terms of their significance for the future of ideas and all that stems from ideas. These diverse, independent, yet interconnected movements pave the way for the emergence of more living and pluralistic approaches to knowledge futures. Higher education researchers, practitioners and policy makers need to take serious account of these dramatic shifts in ideas and ways of organising knowledge. More complex, self-reflective, organic ways of thinking will be vital in re-shaping higher education so young people are better equipped for the complexity, paradox and unpredictability of life in the $21^{\text {st }}$ century.

\section{References}

Adam, B. (2004). Time (Key Concepts). Cambridge, UK: Polity Press.

Aurobindo, S. (1914/2000). The Life Divine. 2nd American Edition. (Originally published in the monthly review Arya 1914-1920). Twin Lakes, WI: Lotus Press.

Bergson, H. (1911/1944). Creative Evolution (A. Mitchell, Trans.). New York: Macmillan \& Co.

Bertalanffy, L. v. (1969/1976). General Systems Theory: Foundations, Development, Applications (Revised Edition). New York: George Braziller, Inc.

Boyer, E. L. (1990). Scholarship reconsidered: Priorities of the professoriate. Princeton, New Jersey: Carnegie Foundation for the Advancement of Teaching.

Commons, M. L., \& Richards, F., A. (2002). Organizing Components into Combination: How Stage Transition Works. Journal of Adult Development, 9(3), 159-177.

Cook-Greuter, S. R. (2000). Mature Ego Development: A Gateway to Ego Transcendence. . Journal of Adult Development, 7(4), 227-240.

Deacon, T. W. (2003). The hierarchic logic of emergence: untangling the interdependence of evolution and self-organisation. In B. Weber \& D. Depew (Eds.), Evolution and Learning: The Baldwin Effect Reconsidered (pp. 273308). Cambridge, MA: MIT Press.

Deem, R., Mok, K. H., \& Lucas, L. (2008). Transforming Higher Education in Whose Image? Exploring the Concept of the 'World-Class' University in Europe and Asia. Higher Education Policy, 21(1), 83-97.

Delors, J. (1996). Learning: The treasure within. Report to UNESCO of the International Commission on Education for the Twenty-first Century. Paris: UNESCO.

Einstein, A. (1920/2000). Relativity: The Special and General Theory (Translated Robert W. Lawson) Available from http://www.bartleby.com/173/

Elgin, D. (1997). Global Consciousness Change: Indicators or an Emerging Paradigm. San Anselmo, CA: The Millennium Project.

Galtung, J., \& Inayatullah, S. (1998). Macrohistory and Macrohistorians. Westport, CT: Praeger.

Gangadean, A. (2006). A Planetary Crisis of Consciousness: From Ego-based Cultures to a Sustainable Global World Kosmos: An Integral Approach to Global Awakening V, 37-39. 
Gebser, J. (1949/1985). The Ever-Present Origin. Athens, Ohio: Ohio University Press.

Gidley, J. (2004). The metaphors of globalisation: A multi-layered analysis of global youth culture. In S. Inayatullah (Ed.), The causal layered analysis (CLA) reader: Theory and case studies of an integrative and transformative methodology. Taipei: Tamkang University.

Gidley, J. (2007). The Evolution of Consciousness as a Planetary Imperative: An Integration of Integral Views. Integral Review: A Transdisciplinary and Transcultural Journal for New Thought, Research and Praxis, 5, 4-226.

Gidley, J. (2009). Educating for evolving consciousness: Voicing the emergenc-y for love, life and wisdom. The International Handbook of Education for Spirituality, Care and Wellbeing. New York: Springer.

Gidley, J. (2010a). Evolving Higher Education Integrally: Delicate Mandalic Theorising. In S. Esbjörn-Hargens, O. Gunnlaugson \& J. Reams (Eds.), Integral Education: New Directions for Higher Learning (pp. 345-361). New York: State University of New York Press.

Gidley, J. (2010b). From Access to Success: An Integrated Approach to Quality Higher Education informed by Social Inclusion Theory and Practice. Higher Education Policy, 23, 123-147.

Gidley, J. (2010c). Globally Scanning for Megatrends of the Mind: Potential Futures of "Futures Thinking". Futures: The journal of policy, planning and futures studies, 42(10), 1040-1048.

Gidley, J. (2010d). An Other View of Integral Futures: De/reconstructing the IF Brand. Futures: The journal of policy, planning and futures studies, 42(2), 125-133.

Goodenough, U., \& Deacon, T. W. (2006). The Sacred Emergence of Nature. In P. Clayton (Ed.), Oxford Handbook of Science and Religion (pp. 853-871). Oxford: Oxford University Press.

Graf, H. G. (2002). Global Scenarios. Megatrends in Worldwide Dynamics Zurich: Verlag Rüegger.

Griffin, D. R. (2002). Introduction to SUNY Series in Constructive Postmodern Thought

. Process and Difference: Between Cosmological and Poststructuralist Postmodernisms (pp. vii-xi). New York: SUNY Press.

Hart, T. (2001). From Information to Transformation: Education for the Evolution of Consciousness. New York: Peter Lang.

Healy, J. M. (1998). Failure to Connect: How Computers Affect Our Children's Minds - and What We Can Do About It. New York: Touchstone.

Huisman, J., \& Van der Wende, M. (2004). The EU and Bologna: Are supra- and international initiatives threatening domestic agendas? European Journal of Education, 39(3), 349-357.

Inayatullah, S., \& Gidley, J. (Eds.). (2000). The University in Transformation: Global Perspectives on the Futures of the University. Westport, Connecticut: Bergin and Garvey.

Jantsch, E. (1980). The Self-Organising Universe: Scientific and Human Implications of the Emerging Paradigm of Evolution New York: Pergamon Press.

Kegan, R. (1994). In Over Our Heads: the Mental Demands of Modern Life. Cambridge, Massachusetts: Harvard University Press. 
Kincheloe, J., \& Steinberg, S. (1993). A Tentative Description of Post-Formal Thinking: The Critical Confrontation with Cognitive Theory. Harvard Educational Review, 63(3), 296-320.

Kincheloe, J., Steinberg, S., \& Hinchey, P. H. (Eds.). (1999). The post-formal reader: Cognition and education New York: Falmer Press.

Klein, J. T. (2004). Prospects for Transdisciplinarity. Futures, 36(4), 515-526.

Kohlberg, L. (1990). Which Postformal Stages are Stages? In M. Commons, C. Armon, L. Kohlberg, F. Richards, A, T. A. Grotzer \& J. D. Sinnott (Eds.), Adult Development, Volume 2: Models and Methods in the Study of Adolescent and Adult Thought. Westport, CT: Praeger.

László, E. (2007). Science and the Akashic Field: An Integral Theory of Everything. Rochester, Vermont: Inner Traditions.

Loye, D. (1998). Darwin's Lost Theory of Love: A Healing Vision for the New Century. Lincoln, NE: iUniverse Inc.

Loye, D. (Ed.). (2004). The Great Adventure: Toward a Fully Human Theory of Evolution. Albany: SUNY Press.

Lunt, I. (2008). Beyond tuition fees? The legacy of Blair's government to higher education. Oxford Review of Education, 34(6), 741-752.

MacLure, M. (2006, November). 'The bone in the throat': some uncertain thoughts on baroque method. Paper presented at the Engaging Pedagogies, AARE 2006 International Education Research Conference, Adelaide.

Mandt, A. J. (1986). The Triumph of Philosophical Pluralism? Notes on the Transformation of Academic Philosophy. Proceedings and Addresses of the American Philosophical Association, 60(2), 265-277.

Marginson, S. (2004). Competition and Markets in Higher Education: A 'glonacal' analysis. Policy Futures in Education, 2(2), 175-244.

Marginson, S. (Ed.). (2007). Prospects of Higher Education: Globalization, Market Competition, Public Goods and the Future of the University. Rotterdam, The Netherlands: Sense Publishers.

Mohrman, K., Ma, W., \& Baker, D. (2008). The Research University in Transition: The Emerging Global Model. Higher Education Policy, 21(1), 5-27.

Molz, M., \& Gidley, J. (2008). A transversal dialogue on integral education and planetary consciousness: Markus Molz speaks with Jennifer Gidley. Integral Review: A Transdisciplinary and Transcultural Journal for New Thought, Research and Praxis, 6, 47-70.

Montuori, A. (1999). Planetary culture and the crisis of the future. World Futures: the Journal of General Evolution, 54(4), 232-254.

Morin, E. (2001). Seven Complex Lessons in Education for the Future. Paris: UNESCO.

Morin, E., \& Kern, A. B. (1999). Homeland Earth: A Manifesto for the New Millennium (Translated Sean Kelly, Roger Lapoint Cresskill, NJ: Hampton Press.

Nicolescu, B. (2002). Manifesto of Transdisciplinarity (Translated by Karen-Claire Voss). New York: SUNY Press.

Nicolescu, B. (2003). Definition of Transdisciplinarity [Electronic version]. Rethinking Interdisciplinarity Retrieved March 8, 2008, from http://www.interdisciplines.org/interdisciplinarity/papers/5/24/1/language/en

Nunan, T., George, R., \& McCausland, H. (2005). Inclusive education in universities: Why it is important and how it might be achieved. In K. J. Topping \& S. 
Maloney (Eds.), The RoutledgeFalmer Reader in Inclusive Education. Oxford, UK: Routledge.

Puuka, J., \& Marmelojo, F. (2008). Higher Education Institutions and Regional Mission: Lessons Learnt from the OECD Review Project. Higher Education Policy, 21(2), 217-245.

Ray, P. (1996). The Rise of Integral Culture. Noetic Sciences Review, 37(Spring), 4.

Russell, P. (2000). The Global Brain Awakens: Our Next Evolutionary Step. Melbourne: Element Books.

Sassen, S. (2007). Deciphering the Global: Its Scales, Spaces and Subjects. New York, NY: Routledge.

Sinnott, J. D. (1998). The Development of Logic in Adulthood: Postformal Thought and its Applications. New York: Springer.

Steinberg, S., \& Kincheloe, J. (Eds.). (2004). Kinderculture: the Corporate Construction of Childhood. Boulder, Colorado: Westview Press.

Steiner, R. (1894/1964). The Philosophy of Freedom: The basis for a modern world conception (GA 4) (M. Wilson, Trans.) (Rev. ed.). (Original work published 1894) Spring Valley, NY: The Anthroposophic Press.

Steiner, R. (1904/1993). Knowledge of the Higher Worlds: How is it Achieved? (GA 10) (6th ed.) (D. S. Osmond \& C. Davy, Trans.) (Original German work published 1904) London: Rudolf Steiner Press.

Steiner, R. (1926/1966). The Evolution of Consciousness as Revealed through Initiation Knowledge (GA 227) (2nd ed.) (V. E. W. \& C. D., Trans.). [13 Lectures: Penmaenmawr, N. Wales, August 19 - 31, 1923] (Original published work 1926). London: Rudolf Steiner Press.

Swimme, B. (1992). The Universe Story: From the Primordial Flaring Forth to the Ecozoic Era Celebration of the Unfolding Cosmos. New York: HarperCollins Publishers.

Swimme, B., \& Tucker, M. E. (2006). The Evolutionary Context of an Emerging Planetary Civilization. Kosmos: An Integral Approach to Global Awakening, $V, 7-8$.

Teilhard de Chardin, P. (1959/2004). The Future of Man. New York: Image Books, Doubleday.

Thompson, W. I. (1998). Coming into Being: Artifacts and Texts in the Evolution of Consciousness. London: MacMillan Press Ltd.

Varela, F., Thompson, E., \& Rosch, E. (1993). The Embodied Mind: Cognitive Science and Human Experience. Cambridge, Massachusetts: The MIT Press.

Weik, E. (2004). From Time to Action: The contribution of Whitehead's philosophy to a theory of action. Time \& Society, 13(2/3), 301-319.

Welch, A. R., \& Zhen, Z. (2008). Higher Education and Global Talent Flows: Brain Drain, Overseas Chinese Intellectuals, and Diasporic Knowledge Networks. Higher Education Policy, 21(4), 519-537.

Whitehead, A. N. (1929/1985). Process and Reality. New York: Free Press.

Wilber, K. (1980/1996). The Atman Project: A Transpersonal View of Human Development (2nd ed.). Wheaton, IL: Quest Books.

Wilber, K. (1981/1996). Up from Eden: A Transpersonal View of Human Evolution (2nd ed.). Wheaton, IL: Quest Books.

Zajonc, A. (Ed.). (2004). The New Physics and Cosmology: Dialogues with the Dalai Lama. New York: Oxford University Press. 